\title{
Infection control and the burden of tuberculosis infection and disease in health care workers in china: a cross-sectional study
}

\author{
Guang Xue He ${ }^{1,2^{*}}$, Susan van den Hof ${ }^{2,3}$, Marieke J van der Werf ${ }^{2,3}$, Guo Jie Wang ${ }^{4}$, Shi Wen Ma ${ }^{4}$, \\ Dong Yang Zhao ${ }^{4}$, Yuan Lian $\mathrm{Hu}^{1}$, Shi Cheng Yu${ }^{5}$, Martien W Borgdorff ${ }^{2}$
}

\begin{abstract}
Background: Hospitals with inadequate infection control are risky environments for the emergence and transmission of tuberculosis (TB). We evaluated TB infection control practices, and the prevalence of latent TB infection (LTBI) and TB disease and risk factors in health care workers (HCW) in TB centers in Henan province in China.
\end{abstract}

Methods: A cross-sectional survey was conducted in 2005. To assess TB infection control practices in TB centers, checklists were used. HCW were tuberculin skin tested (TST) to measure LTBI prevalence, and were asked for sputum smears and chest X-rays to detect TB disease, and questionnaires to assess risk factors. Differences between groups for categorical variables were analyzed by binary logistic regression. The clustered design of the study was taken into account by using a multilevel logistic model.

Results: The assessment of infection control practices showed that only in a minority of the centers the patient consultation areas and X-ray areas were separated from the waiting areas and administrative areas. Mechanical ventilation was not available in any of the TB centers. N95 respirators were not available for HCW and surgical masks were not available for TB patients and suspects. The LTBI prevalence of HCW with and without BCG scar was 55.6\% (432/777) and 49.0\% (674/1376), respectively ( $P=0.003)$. Older HCW, HCW with longer duration of employment, and HCW who worked in departments with increased contact with TB patients had a higher prevalence of LTBI. HCW who work in TB centers at the prefecture level, or with an inpatient ward also had a higher prevalence of LTBI. Twenty cases of pulmonary TB were detected among $3746 \mathrm{HCW}$. The TB prevalence was 6.7/1000 among medical staff and 2.5/1000 among administrative/logistic staff.

Conclusion: TB infection control in TB centers in Henan, China, appears to be inadequate and the prevalence of LTBI and TB disease among HCW was high. TB infection control practices in TB centers should be strengthened in China, including administrative measures, renovation of buildings, and use of respirators and masks. Regular screening of HCW for TB disease and LTBI needs to be considered, offering preventive therapy to those with TST conversions.

\section{Background}

China has the second largest number of tuberculosis (TB) cases in the world [1], and also is one of the countries with high levels of drug resistant TB [2]. Based on the data of the $4^{\text {th }}$ national TB epidemiological survey in

\footnotetext{
* Correspondence: heguangxue@chinatb.org

'National Center for TB control and prevention, China Center for Disease Control and Prevention (CDC), Changping District 102206, Beijing, China Full list of author information is available at the end of the article
}

2000 [3], it is estimated that there were 4.5 million prevalent TB cases in China, of which 1.96 million were pulmonary, bacteriologically confirmed cases. Based on a recent national anti-tuberculosis drug resistance survey, it was estimated that approximately 120,000 new multi-drug resistant (MDR) TB cases emerge annually in China, including 9,000 extensively drug-resistant $\mathrm{TB}$ (XDR-TB) cases, accounting for approximately $24 \%$ of the global burden of MDR-TB [4]. 
Hospitals with inadequate infection control are risky environments for the emergence and transmission of respiratory infectious diseases, such as TB $[5,6]$. Multiple studies have documented the risk of TB transmission from patients to health care workers (HCW) and from patients to patients in low, medium, and high resource settings $[7,8]$. A diverse number of risk factors have been identified, most of which are related to prolonged, unprotected exposure to inpatients with untreated TB $[7,8]$. HCW surveillance, combined with administrative measures and appropriate exposure-based use of personal protective materials and environmental equipment, has helped reduce transmission of TB in some hospitals [9].

In most of the world, respiratory infection control in health care facilities remains inadequate [10]. A health care facility in South Africa was implicated as the initial site of transmission for the first documented outbreak of MDR-TB [11]. Earlier, inadequate infection control in hospitals had already led to large outbreaks of MDR-TB [12]. These outbreaks have turned attention to the need to reduce TB transmission in health care facilities [2]. New World Health Organization (WHO) guidelines on TB infection control have been released in 2009 and call on countries to institute programs to screen for TB regularly in $\mathrm{HCW}$ and to routinely record and report this data [10]. Health care facilities in China do not routinely screen HCW for latent TB infection (LTBI) and TB disease. Until recently, there was no national TB infection control policy, and also no occupational TB policy in place in China. However, the high number of MDR-TB cases in China, many of whom receive prolonged treatment in hospitals, adds to the importance of screening $\mathrm{HCW}$ and preventing nosocomial transmission of (MDR-) TB.

In order to measure the prevalence of LTBI and TB disease in Chinese $\mathrm{HCW}$, we conducted a study in Henan province, the province in China with the largest population size (97 million) and a high proportion of MDR-TB cases (12.9\% in 2001 [13]). We assessed TB infection control practices in the TB centers, and the prevalence of LTBI and TB disease in its HCW. This would be the first study documenting the prevalence of LTBI and TB disease among HCW in China in the international scientific literature.

\section{Methods}

Research methods

\section{Study design, population and sampling}

We conducted a cross-sectional survey on HCW from TB centers in Henan province, China. Henan province is divided into 18 prefecture-level administrative areas and the prefectures into 158 counties/districts. In each administrative level in Henan province, there is one TB center that is responsible for implementing its respective TB program. However, not every TB center has its own TB clinic. Each prefecture level and 109 (69\%) of county/district level TB centers have TB clinics, while 49 of them do not. Of those with a TB clinic, 33 (26\%) TB centers had an inpatient TB ward; 18 (100\%) at prefecture level and 15 (14\%) at county level (Figure 1).

All 127 TB centers with TB clinics were included in the survey on TB infection control practices and prevalence of TB disease among HCW. For the survey on LTBI, all $18 \mathrm{~TB}$ centers at the prefecture level and 40 randomly selected TB centers at the county/district level were included.

\section{Data collection}

The provincial level TB center staff conducted a pilot study in Zhumadian city in December 2004. The data are included in the study results. Provincial level staff trained prefecture level project staff in January 2005. Prefecture project staff then trained county/district project staff. The field investigation was conducted from January 17 to March 31, 2005.

Project staff from prefecture and county/district level filled in a checklist on prevailing TB infection control practices in their own center. To assess TB disease prevalence, chest X-rays were done on all $\mathrm{HCW}$ after they provided informed consent. Three sputum smears (spot, morning, evening) were examined following the WHO standard for HCW with an abnormal chest radiograph or cough longer than two weeks. All participants were asked to fill in a questionnaire on demographic characteristics and TB symptoms at the time of their X-ray examinations.

A TST was done on all HCW in the subset of 58 facilities, unless they declined to participate or were not available during the study period. In China, BCG vaccination is highly recommended by health authorities since the late 1970s and is usually given to all newborns within the first few days of life. No booster vaccinations

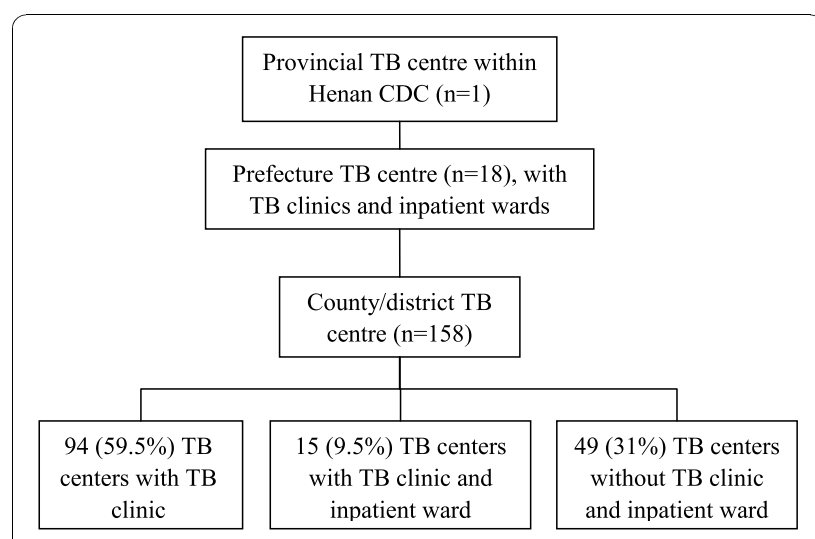

Figure 1 Illustration of TB control system in Henan province. 
are recommended in China. Therefore, the influence of BCG on the TST result is expected to be minor $[8,14]$.

TST were conducted according to WHO procedures [15]. Chinese-made purified-protein derivative (PPD), 0.1 $\mathrm{ml}, 5$ Tuberculin Unit was injected subcutaneously on the volar surface of the left forearm and the induration measured at 48-72 hours. Studies in China showed that the purity of the local PPD was similar to the international standard PPD (PPD-RT23) [16]. In direct comparison studies stability, safety, reaction size, and conversion rate also were similar $[17,18]$. TSTs were administered by 18 nurses who have attended a provincial training course and passed a qualification exam set up for this study. Each participant in the investigation was carefully examined for the presence of a Bacille de Calmette Guerin (BCG) scar before testing in order to ascertain the participant's vaccination status. Similar to other studies, we used TST induration $\geq 10 \mathrm{~mm}$ as a cut-off point [19-21], and defined the diagnosis of LTBI as a TST result with an induration $\geq 10 \mathrm{~mm}[7,22]$.

\section{Quality control}

In order to implement the survey successfully, provincial coordination and technical groups were established. The coordination group was responsible for organizing and coordinating the implementation of the study. The technical group was responsible for the training of prefecture level project staff, quality control, and checking and collecting all data. A research group was established in each prefecture and was responsible for organizing the field work and for quality control. The research group included TB control staff, TST technicians, and a deputy director of a TB center as the head of the group.

The provincial level technical group personnel and principal investigators reviewed all data collected each day to ensure that data were recorded legibly, completely, and consistently. The provincial technical group also conducted site visits to ensure quality of the data and sputum collection and examination.

\section{Data analysis}

Data were double entered using Epi Data 3.1 (The Epi Data Association, Odense, Denmark, 2003-2008) and checked for discrepancies between the two entries. Differences between groups for the distribution of categorical variables were analyzed by binary logistic regression. Odds ratios (OR) are presented with their 95\% confidence intervals $(\mathrm{CI})$.

The TST data showed terminal-digit preference. To smooth the data, we applied a five-point moving average. We compared TST results in HCW with and without BCG scar. The association of TST results with variables of interest was examined using a logistic regression model. We took the clustered design of the study into account by using a multilevel logistic model with two levels: the TB center and the individual staff members within the TB centers. Variables collected at the TB center level were prefecture versus county/district level, size of the TB center as measured by number of staff employed, and presence of an inpatient ward. Variables collected at the individual level included sex, age, position, job location, education, years of employment in this TB center, income, smoking and alcohol use. The test for the clustering effects showed a significant difference among TB centers, so a random effect logistic regression model was used. MLwiN Version 2.02 (Rasbash, J., Charlton, C., Browne, W.J., Healy, M. and Cameron, B. (2005) MLwiN Version 2.02. Centre for Multilevel Modeling, University of Bristol) was used for fitting the model.

\section{Ethical issues}

The research project was approved by the Chinese Ethical Committee for TB Operational Research in Beijing. The research staff provided HCW with basic background information about the study. Participants were then asked to read documentation themselves and provide written informed consent. The participants were informed of their sputum smear, chest X-ray, and TST results. All persons identified as having TB disease were advised to start treatment at the local TB center. Treatment for LTBI is not routinely offered in China. Those with positive TST results were informed that they should pay particular attention to TB symptoms because they are at higher risk of developing active $\mathrm{TB}$.

\section{Results}

\section{TB infection control situation}

Of the 127 TB centers, 33 (26.0\%) had pre-employment screening of HCW for TB disease in place, and 62 (48.8\%) had a screening program for HCW that included annual screening using $\mathrm{X}$-ray and physical examination during employment. The patient consultation areas and $\mathrm{X}$-ray areas were in different rooms than the waiting areas and administrative areas in a minority of the TB centers (Table 1). Mechanical ventilation was not available in any TB center. TB center staff reported that windows were often opened in $43 \%-67 \%$ of patient consultation rooms, sputum examination rooms and $\mathrm{X}$ ray rooms. 116 (91.3\%) consultation rooms, 121 (95.3\%) sputum examination rooms and $73(57.5 \%)$ X-ray rooms had ultraviolet (UV) lights that were situated at upper room. In rooms with UV lights, the UV lights were used daily in $71(61.2 \%)$ patient consultation rooms, 80 (66.1\%) sputum examination rooms and 33 (45.2\%) X-ray rooms. Only a minority of UV lights was tested regularly, and less than half of them were cleaned monthly. N95 respirators were not available for $\mathrm{HCW}$ and surgical masks were not available for TB patients and suspects.

\section{LTBI prevalence}

TST was employed in 2153 (94.1\%) out of 2288 $\mathrm{HCW}$ in the 58 selected TB centers. Of the 135 


\begin{tabular}{|c|c|c|c|c|c|c|c|}
\hline & \multirow{2}{*}{$\begin{array}{l}\text { Separated from } \\
\text { waiting room } \\
\text { n (\%) }\end{array}$} & \multirow{2}{*}{$\begin{array}{l}\text { Separated from } \\
\text { administrative area. } \\
\text { n (\%) }\end{array}$} & \multirow{2}{*}{$\begin{array}{l}\text { Open windows } \\
\text { often* } \\
\text { n (\%) }\end{array}$} & \multicolumn{4}{|c|}{ UVGI } \\
\hline & & & & $\begin{array}{l}\text { Available } \\
\text { n (\%) }\end{array}$ & $\begin{array}{l}\text { Used } \\
\text { daily } \\
\text { n (\%) }\end{array}$ & $\begin{array}{l}\text { Tested } \\
\text { Regularly** } \\
\text { n (\%) }\end{array}$ & $\begin{array}{l}\text { Cleaned } \\
\text { monthly } \\
\mathrm{n}(\%)\end{array}$ \\
\hline $\begin{array}{l}\text { Patient consultation } \\
\text { room }\end{array}$ & $14(11.0)$ & $18(14.2)$ & $83(65.4)$ & $116(91.3)$ & $\begin{array}{l}71 \\
(61.2)\end{array}$ & $13(11.2)$ & $57(49.1)$ \\
\hline $\begin{array}{l}\text { Sputum } \\
\text { examination room }\end{array}$ & $108(85.0)$ & $20(15.7)$ & 85 (66.9) & $121(95.3)$ & $\begin{array}{l}80 \\
(66.1)\end{array}$ & $18(14.9)$ & $58(47.9)$ \\
\hline X-ray room & 38 (29.9) & 35 (27.6) & $55(43.3)$ & $73(57.5)$ & $\begin{array}{l}33 \\
(45.2)\end{array}$ & $9(12.3)$ & $34(46.5)$ \\
\hline
\end{tabular}

UVGI = Ultraviolet germicidal irradiation.

* daily opened in summer all day and daily opened in winter for short time.

** Quarterly tested or half-yearly tested.

non-respondents, 71 were working at a different location on the day the TST was applied, 30 were working at a different location on the day the TST was read, 20 were on holiday, and 34 decided to not participate. The mean age of the $2153 \mathrm{HCW}$ was 37 (18-61) years old, 1163 (54.0\%) were female, and 990 (45.0\%) were male. Despite training, terminal-digit preference was visible at 10,15 , and $20 \mathrm{~mm}$. An analysis of smoothed data indicated that there was no apparent bimodal distribution in HCW with or without BCG scar. Large TST indurations ( $\geq 15 \mathrm{~mm}$ ) were more frequent in those with BCG scars (Figure 2). LTBI prevalence in those with and without BCG scar was 55.6\% (432/777) and 49.0\% (674/1376), respectively $(\mathrm{OR}=1.3,95 \% \mathrm{CI}=1.1-1.6) .36 .7 \%(534 /$ $1455)$ of medical staff and $34.8 \%$ (243/698) of administrative/logistic staff had BCG scars (OR $=1.1$, 95\%CI $=0.9-1.3$.

LTBI was associated with working at a TB center at the prefecture level, older age, longer duration of employment, presence of BCG scar, employment at a TB center with an inpatient ward, and job location within the TB center. Administrative/logistic staff and pharmacy staff had the lowest prevalence of LTBI (Table 2); LTBI prevalence in medical versus administrative/logistic staff was $55.7 \%(811 / 1455)$ and $42.3 \%$ $(295 / 698)$, respectively $(\mathrm{OR}=1.7,95 \% \mathrm{CI}=1.4-2.1)$. Some factors associated with TST induration size $\geq 10$ mm were similar for $\mathrm{HCW}$ with compared to those without a BCG vaccination scar, including age, job location, duration of employment, inpatient ward, and level.

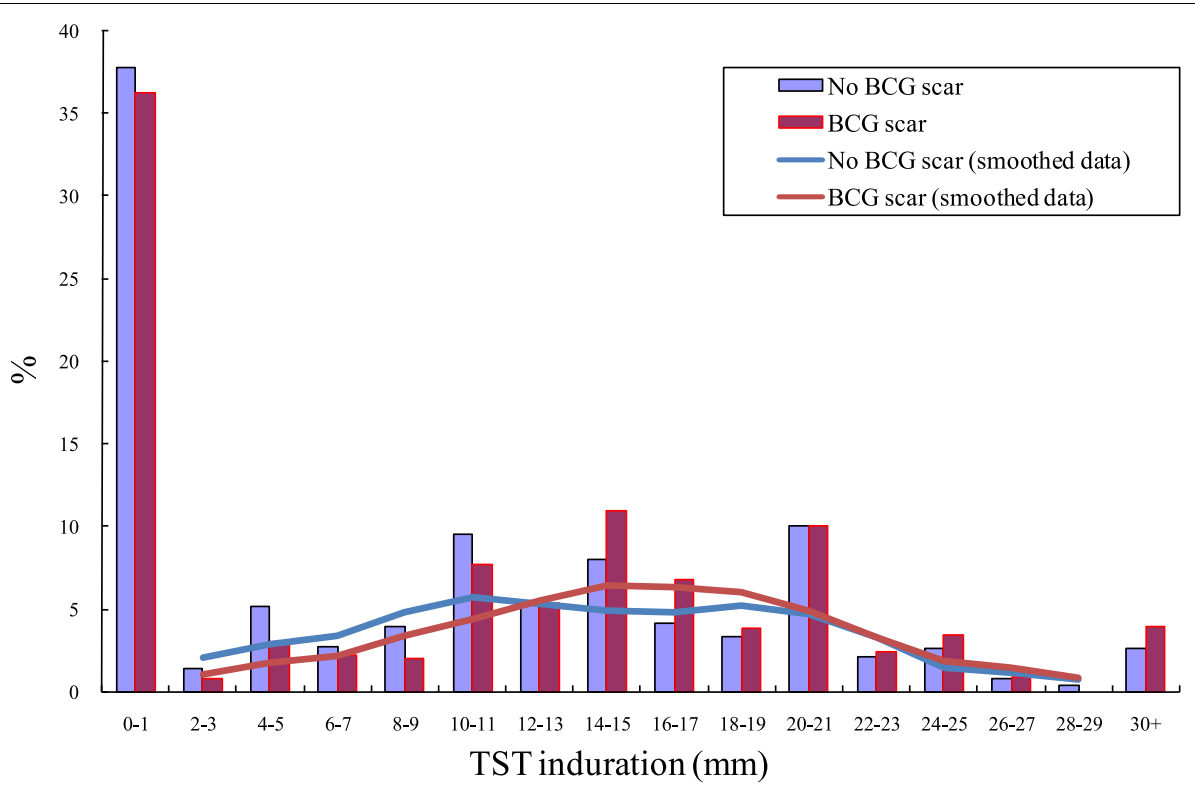

Figure 2 Distribution of TST induration sizes among 2153 HCWs with BCG and without BCG vaccination scar. 
Table 2 Risk factors of latent tuberculosis infection (LTBI) among 2153 health care workers

\begin{tabular}{|c|c|c|c|c|c|c|c|}
\hline Variable & & HCW N (\%) & Induration $\geq 10 \mathrm{~mm} \mathrm{n} \mathrm{( \% )}$ & $\begin{array}{l}\text { Crude } \\
\text { Cl) }\end{array}$ & OR $(95 \%$ & $\begin{array}{l}\text { Adjustec } \\
\text { CI) }\end{array}$ & d OR* $(95 \%$ \\
\hline Gender and smoking & Male, non-smoker & $526(24.4)$ & $253(48.1)$ & 1 & & & \\
\hline & Male, smoker & $464(21.6)$ & $244(52.6)$ & 1.2 & $(0.9-1.5)$ & & \\
\hline & Female & $1163(54.0)$ & $609(52.4)$ & 1.2 & $(0.9-1.5)$ & & \\
\hline Age group (years) & $18-29$ & $580(26.9)$ & $229(39.5)$ & 1 & & 1 & \\
\hline & $30-39$ & $740(34.4)$ & $399(53.9)$ & 1.8 & $(1.4-2.2)$ & 1.6 & $(1.2-2.1)$ \\
\hline & $40-49$ & $615(28.6)$ & $343(55.8)$ & 1.9 & $(1.5-2.4)$ & 1.8 & $(1.3-2.5)$ \\
\hline & $\geq 50$ & $218(10.1)$ & $135(61.9)$ & 2.5 & $(1.8-3.4)$ & 2.6 & $(1.7-4.0)$ \\
\hline BCG scar & No & $1376(63.9)$ & $674(49.0)$ & 1 & & 1 & \\
\hline & Yes & $777(36.1)$ & $472(55.6)$ & 1.3 & $(1.1-1.6)$ & 1.4 & $(1.1-1.7)$ \\
\hline Income (Yuan/Year) & $<15000$ & $1106(51.4)$ & $528(47.7)$ & 1 & & & \\
\hline & 15000-19999 & $691(32.1)$ & $361(52.2)$ & 1.2 & $(1.0-1.5)$ & & \\
\hline & 20000-29999 & $298(13.8)$ & $182(61.1)$ & 1.7 & $(1.3-2.2)$ & & \\
\hline & $>30000$ & $58(2.7)$ & $35(60.3)$ & 1.7 & $(1.0-2.9)$ & & \\
\hline Education & Primary or middle school & $63(2.9)$ & $28(44.4)$ & 1 & & & \\
\hline & Secondary school & $976(45.3)$ & $450(46.1)$ & 1.1 & $(0.6-1.8)$ & & \\
\hline & Junior college & $898(41.7)$ & $496(55.2)$ & 1.5 & $(0.9-2.6)$ & & \\
\hline & University or above & $216(10.1)$ & $132(61.1)$ & 2.0 & $(1.1-3.5)$ & & \\
\hline Position & Junior & $1270(59.0)$ & $594(46.8)$ & 1 & & & \\
\hline & Middle & $697(32.4)$ & $414(59.4)$ & 1.7 & $(1.4-2.0)$ & & \\
\hline & Senior & $186(8.6)$ & $98(52.7)$ & 1.3 & $(0.9-1.7)$ & & \\
\hline Job location & Administrative/logistic & $698(32.4)$ & $295(42.3)$ & 1 & & 1 & \\
\hline & TB outpatient clinic & $609(28.3)$ & $333(54.7)$ & 1.7 & $(1.3-2.1)$ & 1.9 & $(1.4-2.6)$ \\
\hline & TB inpatient ward & $165(7.7)$ & $101(61.2)$ & 2.2 & $(1.5-3.1)$ & 1.3 & $(1.0-2.1)$ \\
\hline & Supervision and monitoring & $234(10.9)$ & $132(56.4)$ & 1.8 & $(1.3-2.4)$ & 1.6 & $(1.2-2.3)$ \\
\hline & Pharmacy & $147(6.8)$ & $74(50.3)$ & 1.4 & $(1.0-2.0)$ & 1.0 & $(0.7-1.6)$ \\
\hline & X-ray department & $122(5.6)$ & $78(63.9)$ & 2.4 & $(1.6-3.6)$ & 1.8 & $(1.1-2.9)$ \\
\hline & Laboratory & $178(8.3)$ & $93(52.2)$ & 1.5 & $(1.1-2.1)$ & 1.4 & $(0.9-2.0)$ \\
\hline Duration of employment (years) & $<1$ & $810(37.6)$ & $295(36.4)$ & 1 & & 1 & \\
\hline & $1-4$ & $374(17.4)$ & $166(44.4)$ & 1.4 & $(1.1-1.8)$ & 1.4 & $(1.0-1.9)$ \\
\hline & $5-9$ & $323(15.0)$ & $188(58.2)$ & 2.4 & $(1.9-3.2)$ & 2.3 & $(1.6-3.1)$ \\
\hline & $\geq 10$ & $646(30.0)$ & $457(70.7)$ & 4.2 & $(3.4-5.3)$ & 3.0 & $(2.2-4.1)$ \\
\hline Inpatient ward & No & $1094(50.8)$ & $436(39.9)$ & 1 & & 1 & \\
\hline & Yes & $1059(49.2)$ & $670(63.3)$ & 2.6 & $(2.2-3.1)$ & 2.3 & $(1.9-2.9)$ \\
\hline Size of clinic (No. of staff) & $<25$ & $348(16.2)$ & $179(51.4)$ & 1 & & & \\
\hline & $25-39$ & $600(27.9)$ & $268(44.7)$ & 0.8 & $(0.6-0.9)$ & & \\
\hline & $\geq 40$ & $1205(56.0)$ & $659(54.7)$ & 1.1 & $(0.9-1.5)$ & & \\
\hline Level & County/District & $1282(59.6)$ & $538(42.0)$ & 1 & & 1 & \\
\hline & Prefecture & $871(40.4)$ & $568(65.2)$ & 2.8 & $(2.3-3.3)$ & 1.8 & $(1.0-3.5)$ \\
\hline
\end{tabular}

${ }^{*}$ Adjusted for all other factors included in the multivariate model.

$\mathrm{HCW}=$ health care worker; $\mathrm{OR}=$ odds ratio; $\mathrm{Cl}=$ confidence interval; $\mathrm{TB}=$ tuberculosis.

TB disease prevalence

In the $127 \mathrm{~TB}$ centers, all HCW gave consent to be screened. Among the $3759 \mathrm{HCW}, 3746$ (99.7\%) were investigated for pulmonary TB disease, and the rest 13 $(0.3 \%)$ were absent from work during the investigation. The mean age of the $3746 \mathrm{HCW}$ was 37 (18-61) years old, 1937 (51.7\%) were female, and 1809 (48.8\%) were male. Among the $3746 \mathrm{HCW}, 86$ (2.3\%) reported TB symptoms, 54 (1.4\%) had an abnormal chest X-ray, and only $9(0.2 \%)$ had both TB symptoms and an abnormal chest X-ray. Twenty $(0.5 \%)$ cases of pulmonary TB were detected including 18 new cases and 2 retreatment cases, and 3 out of 20 cases were diagnosed as new smear-positive cases. The overall point prevalence was 5.3/1000; 6.7/1000 among medical staff and 2.5/1000 among administrative/logistic staff $(\mathrm{OR}=2.7,95 \% \mathrm{CI}=$ 0.8-9.3). HCW with longer duration of employment seemed at increased risk of active TB; the TB prevalence was 3.7/1000 among HCW who worked for less than 5 years in the facility and 7.5/1000 among HCW who 
worked for $\geq 5$ years in the facility $(\mathrm{OR}=2.0,95 \% \mathrm{CI}=$ 0.8-4.9). The prevalence for HCW working with $\mathrm{TB}$ inpatients was $15.2 / 1000$, which was much higher than in $\mathrm{HCW}$ working in any other job location $(\mathrm{OR}=3.2$, $95 \% \mathrm{CI}=1.1-11.1)$. There were only 9 female smokers out of 1937 (4.6/1000) female HCWs, so we combined gender and smoking into three subgroups: females, male non-smokers, and male smokers. TB prevalence in male smokers was 9.6/1000 and was higher than in male nonsmokers $(\mathrm{OR}=9.5,95 \%=1.2-75.9)$ (Table 3). There was no significant difference in TB disease prevalence by age, BCG scar, job location, and administrative level of the TB center.

The identified TB patients had TST induration sizes that ranged from $6 \mathrm{~mm}$ to $50 \mathrm{~mm}$, with a median of 20 $\mathrm{mm}$. Only one patient had an induration $<10 \mathrm{~mm}$. In the $2153 \mathrm{HCW}$ with TST results, TB disease prevalence in HCW with TST induration $<10 \mathrm{~mm}$ was $1.0 / 1000$, and in HCW with TST induration $\geq 10 \mathrm{~mm}$ was 11.8 / $1000(\mathrm{OR}=12.4,95 \% \mathrm{CI}=1.6-95.3)$. $\mathrm{TB}$ prevalence increased with larger TST induration sizes (Table 3).

\section{Discussion}

Some aspects of TB infection control in TB centers as evaluated in this study appeared inadequate in Henan province of China. The prevalence of LTBI and TB disease among HCW was higher than observed in the national TB prevalence survey in 2000 [3]. The LTBI prevalence of $56 \%$ among medical staff was higher than the LTBI prevalence of $47 \%$ (using a cut-off point of $6 \mathrm{~mm}$ ) in the general population group of 15 years or older from the survey in 2000. So even with a higher TST cut-off point, the estimated prevalence of LTBI amongst HCW was still higher than the prevalence in the general population group of 15 years or older in a survey conducted five years earlier. We observed a TB disease prevalence of 5.3/1000 among HCW compared to $3.0 / 1000$ in the 15-59 year old age group in the prevalence survey. The age- and sex-stratified prevalence in the 2000 survey were applied to calculate the expected number of cases in 2005 in HCW. The calculation indicated 12 expected active TB cases but instead our study found 20 cases, which was much higher than estimated $(\mathrm{RR}=1.67,95 \% \mathrm{CI}=1.02-2.57)$.

Table 3 Tuberculosis prevalence in $\mathbf{3 7 4 6}$ health care workers in Henan province, China

\begin{tabular}{|c|c|c|c|c|}
\hline Item & & No. of HCW & No. of TB & Prevalence $(1 / 1000)$ \\
\hline \multirow[t]{3}{*}{ Gender and smoking* } & Male, non-smoker & 977 & 1 & 1.0 \\
\hline & Male, smoker & 832 & 8 & 9.6 \\
\hline & Female & 1937 & 11 & 5.7 \\
\hline \multirow[t]{4}{*}{ Age group (years) } & $18-29$ & 988 & 6 & 6.1 \\
\hline & $30-39$ & 1295 & 5 & 3.9 \\
\hline & $40-49$ & 1070 & 7 & 6.5 \\
\hline & $\geq 50$ & 393 & 2 & 5.1 \\
\hline \multirow[t]{2}{*}{ BCG scar } & No & 2451 & 13 & 5.3 \\
\hline & Yes & 1294 & 7 & 5.4 \\
\hline \multirow[t]{7}{*}{ Job location } & TB outpatient clinic & 1187 & 9 & 7.6 \\
\hline & TB inpatient ward & 197 & 3 & 15.2 \\
\hline & Supervision and monitoring & 383 & 1 & 2.6 \\
\hline & Pharmacy & 255 & 1 & 3.9 \\
\hline & X-ray & 204 & 1 & 4.9 \\
\hline & Laboratory & 305 & 2 & 6.6 \\
\hline & Administrative/logistic & 1215 & 3 & 2.5 \\
\hline \multirow[t]{4}{*}{ Duration of employment (years) } & $<1$ & 1383 & 5 & 3.6 \\
\hline & $1-4$ & 757 & 3 & 4.0 \\
\hline & $5-9$ & 613 & 6 & 9.8 \\
\hline & $\geq 10$ & 993 & 6 & 6.0 \\
\hline \multirow[t]{2}{*}{ Level } & Prefecture & 869 & 5 & 5.8 \\
\hline & County/District & 2877 & 15 & 5.2 \\
\hline \multirow[t]{3}{*}{ TST induration $(\mathrm{mm})^{\S_{1}, \#}$} & $0-9$ & 1047 & 1 & 1.0 \\
\hline & $10-19$ & 687 & 6 & 8.7 \\
\hline & $20+$ & 419 & 7 & 16.7 \\
\hline
\end{tabular}

* Male smoker: $\mathrm{OR}=9.5,95 \% \mathrm{Cl}=1.2-75.9 ;$ Female: $\mathrm{OR}=5.6,95 \% \mathrm{Cl}=0.7-43.2$.

$\S$ in $2153 \mathrm{HCW}$ with TST results including 14 TB cases.

\# 10-19 compared to $0-9: \mathrm{OR}=9.2,95 \% \mathrm{Cl}=1.1-76.6 ; 20+$ compared to $0-9: \mathrm{OR}=17.6,95 \% \mathrm{Cl}=2.2-143.5$.

$\mathrm{HCW}=$ health care worker; TB = tuberculosis; TST = tuberculin skin test. 
Studies elsewhere showed varying LTBI rates amongst $\mathrm{HCW}[7,8,20,21,23]$. Our results from Henan province showed high LTBI rates amongst HCW similar to other studies in low and middle income countries and compared well with an average LTBI prevalence of $54 \%$ among HCW [8]. The prevalence of LTBI among HCW in high-income countries was generally lower [24,25]. Our study results are also consistent with studies that show an increasing prevalence of LTBI with increasing age, work locations with higher exposure to TB patients (especially TB outpatient clinics, inpatient wards, and $\mathrm{X}$-ray departments), and longer duration of employment at the health care facility $[7,8,20,23]$. In our study, working at a TB center at the prefecture level and presence of an inpatient ward at the TB center were associated with a higher LTBI prevalence among staff members. At prefecture level, all TB centers had TB clinics and inpatient wards. Patients with more severe TB disease likely attend a prefecture TB center for medical care, which may increase the exposure to TB at prefecture level. Although the association of male sex with increased $M$. tuberculosis infection risk has been reported [19], we did not observe this (OR $=1.1,95 \% \mathrm{CI}: 0.9-1.3)$. However, we did observe that male smokers had an increased prevalence of TB disease compared with non-smokers, as shown before [26].

This study suggests that nosocomial transmission of TB is an important occupational problem among HCW. The reduction of this risk should be a priority. Occupational contracted TB can lead to the loss of skilled workers, and this can adversely impact on health care services in the long term. Medical workers may also avoid working with TB centers due to the high risk of TB transmission to HCW. TB amongst HCW can have serious, and even fatal, consequences. This problem is particularly serious with MDR-TB strains. Hospitals have been shown to be important focal points of MDRTB transmission, resulting in explosive outbreaks $[27,28]$. Implementation of effective TB infection control measures can promote awareness of the disease among HCW, and help in the adoption of good practices for diagnosis and treatment of TB.

Most of the TB centers in China are in older buildings, and therefore are not designed in line with TB infection control standards [10]. Therefore, we suggest beginning implementation of some simple yet highly effective interventions, such as fast identification of TB suspects, segregation of infectious TB patients, and education as well as training for HCW [10]. Administrative interventions that improve the current situation in health care facilities require minimal resources and can be easily implemented. Engineering controls such as exhaust ventilation, improved natural ventilation [29], and the use of UV lights are also cost-effective measures to minimize the risk of TB infection [10]. National TB control and public health authorities should focus on addressing nosocomial TB transmission as an integral part of the TB control program. HCW are essential in the fight against TB, and their health should be protected as well as that of patients. With the emergence of XDR-TB, the need to implement TB infection control measures has been reemphasized by the WHO and the Stop TB Partnership [30]. After the study results became available, TB centers in Henan province have strengthened training on TB infection control for HCW and paid more attention to ventilation systems and adequate UV light use.

There are several limitations to our study. The trained project staff filled in the checklists for their own centers, and therefore the staff might not have been completely honest about prevailing TB infection control practices in their own centers. Even with intensive training for TST nurses, the terminal-digit preference was visible at 10 , 15 , and $20 \mathrm{~mm}$. The preference for cut-off point of 10 $\mathrm{mm}$ in TST results may have caused a slight overestimation of HCW with LTBI. Our results showed that people with BCG vaccination had higher prevalence of LTBI. BCG vaccination can also lead to positive results of the TST, thus we may have overestimated the LTBI rate in BCG vaccination group. However, a couple of international reviews have reported that the influence of BCG is relatively small in the adult population, especially $\geq$ 10 years after BCG vaccination $[8,14]$. Misclassification of BCG vaccination status may have occurred as not all of those vaccinated develop a scar. However, the presence of a BCG scar has been found to be a good indicator of BCG vaccination [31] and several studies reported that $95-100 \%$ people had a BCG scar after BCG vaccination [31-33] so misclassification should be limited. Exclusion of those with BCG scar did not affect results. LTBI or TB disease in a HCW may be due to infection acquired nosocomially or in the community. We were unable to differentiate between infections acquired in the community versus in the center, but LTBI prevalence in medical staff (56\%) was significantly higher than that in administrative/logistic staff (42\%) in the same TB center. This indicates that at least (( $56-$ $42) / 56)=$ ) $25 \%$ of LTBI in this setting could be attributed to nosocomial infection. We observed a TB disease prevalence that was much higher than observed in the 2000 survey. This may be explained by the fact that the 2000 survey used the chest fluoroscopy, which has a much lower sensitivity than the chest X-ray method, for detecting TB. Moreover, only three of the twenty TB disease cases were smear positive. It might be that we identified some TB patients at very early stage with tiny shadows at the chest X-ray, as the majority did not have any symptoms. 
We are the first to report internationally on prevalence of TB infection and disease among Chinese HCW. As TB infection control was at a very early stage at the time of the study, the infection control situation in most areas of China was likely to be similar to Henan province. In a few MDR-TB project areas in China, the TB infection control policy as recommended by the WHO is now being implemented through the national TB program [10]. TB infection control is insufficient in most areas of China. With a high TB prevalence and limited resources, China focuses largely on case detection and treatment using the DOTS strategy. In some areas, even low-cost strategies to reduce TB transmission in healthcare facilities are seldomly implemented. We strongly suggest that $\mathrm{TB}$ infection control strategies are rapidly implemented, with priority for provinces with high antiTB drug resistance prevalence.

\section{Conclusion}

TB infection control in TB centers in Henan province appeared to be inadequate and the prevalence of LTBI and TB disease among HCW was high. TB infection control practices in TB centers should be strengthened in China, including administrative measures, renovation of buildings, and the use of respirators and masks. Moreover, regular screening of $\mathrm{HCW}$ for TB disease and infection needs to be considered, offering preventive therapy to those with TST conversions.

\section{Acknowledgements}

The authors wish to thank the TB control staff, project staff in Henan province for implementing this project. We thank Mr. Cho-Yau Ling for carefully editing the text.

This study was supported by the China National Key Project (2009ZX10004714; Beijing, China) and the WB/DFID China Tuberculosis Control Project (Research projects 035).

\section{Author details \\ ${ }^{1}$ National Center for TB control and prevention, China Center for Disease Control and Prevention (CDC), Changping District 102206, Beijing, China. ${ }^{2}$ Center for Infection and Immunity Amsterdam (CINIMA), Academic Medical Center, University of Amsterdam, Meibergdreef 9, 1105 AZ, Amsterdam, The Netherlands. ${ }^{3}$ KNCV Tuberculosis Foundation, Parkstraat 17, 2514 JD, The Hague, The Netherlands. ${ }^{4}$ Tuberculosis Control Institute, Henan Provincial Center for Disease Control and Prevention, Xindong Districe 450016, Zhengzhou, China. ${ }^{5}$ National Center for Public Health Surveillance and Information Service, Changping District 102206, China CDC, Beijing, China.}

\footnotetext{
Authors' contributions

GXH participated in the design and coordination of the study, was responsible for data collection, analysis and interpretation of the data and drafted the manuscript. SH assisted in analysis and interpretation of the data, and assisted in drafting the manuscript. MJW assisted in analysis and interpretation of the data, and critically reviewed the manuscript. GJW participated in the design and coordination of the study, was responsible for data collection and interpretation of the data. SWM and DYZ were involved in the design and coordination of the study, was responsible for data collection and interpretation of the data. YLH was responsible for data collection, analysis and interpretation of the data. SCY was responsible for data analysis and interpretation of the data. MWB assisted in analysis and
}

interpretation of the data and critically reviewed the manuscript. All authors reviewed and approved the manuscript.

\section{Competing interests}

The authors declare that they have no competing interests.

Received: 22 May 2010 Accepted: 28 October 2010

Published: 28 October 2010

\section{References}

1. World Health Organization: Global Tuberculosis Control: Epidemiology, Strategy, Financing. WHO Report 2009. Geneva, Switzerland: WHO; 2009.

2. World Health Organization: Multidrug and extensively drug-resistant TB (M/XDR-TB): 2010 global report on surveillance and response. WHO/ HTM/TB/2010.3 Geneva, Switzerland: World Health Organization; 2010.

3. National Technical Steering Group of the Epidemioligical Sampling Survey for Tuberculosis: Report on nationwide random survey for the epidemiology of tuberculosis in 2000. The Journal of the Chinese Antituberculosis Association 2000, 24:65-108.

4. Ministry of Health of the People's Republic of China: Nationwide antituberculosis drug resistant baseline surveillance in China (2007-2008). People's Public Health Press 2010.

5. Lau JT, Fung KS, Wong TW, Chung S, Ho D, Chan LY, Lui SF, Cheng A: SARS transmission among hospital workers in Hong Kong. Emerg Infect Dis 2004, 10:280-286.

6. Kenyon TA, Ridzon R, Luskin-Hawk R, Valway SE, Onorato IM, Castro K: A nosocomialoutbreak of multidrug-resistant tuberculosis. Ann Intern Med 1997, 127:32-36.

7. Menzies D, Joshi R, Pai M: Risk of tuberculosis infection and disease associated with work in health care settings. Int J Tuberc Lung Dis 2007, 11:593-605.

8. Joshi R, Reingold AL, Menzies D, Pai M: Tuberculosis among health-care workers in low and middle-income countries: A systematic review. PLoS Med 2006, 3(12):e494.

9. Cook S, Maw KL, Munsiff SS, Fujiwara Pl, Frieden TR: Prevalence of tuberculin skin test positivity and conversions among healthcare workers in New York City during 1994 to 2001. Infect Control Hosp Epidemiol 2003, 24:807-813.

10. World Health Organization: World Health Organization: Guidelines for the prevention of tuberculosis in health-care facilities in resource-limited settings. . WHO/CDS/TB/99.269 Geneva, Switzerland: World Health Organization; 2009.

11. Sacks LV, Pendle S, Orlovic D, Blumberg L, Constantinou C: A comparison of outbreak- and nonoutbreak-related multidrug-resistant tuberculosis among human immunodeficiency virus-infected patients in a South African hospital. Clin Infect Dis 1999, 29:96-101.

12. Jereb JA, Klevens RM, Privett TD, Smith PJ, Crawford JT, Sharp VL, Davis BJ, Jarvis WR, Dooley SW: Tuberculosis in Health Care Workers at a Hospital With an Outbreak of Multidrug-Resistant Mycobacterium tuberculosis. Arch Intern Med 1995, 155:854-859.

13. He GX, Zhao YL, Jiang GL, Liu YH, Xia H, Wang SF, Wang LX, Borgdorff MW, van der Werf MJ, van den Hof S: Prevalence of tuberculosis drug resistance in 10 provinces of China. BMC Infectious Diseases 2008, 8:166.

14. Wang L, Turner MO, Elwood RK, Schulzer M, FitzGerald JM: A meta-analysis of the effect of Bacille Calmette Guérin vaccination on tuberculin skin test measurements. Thorax 2002, 57:804-809.

15. Arnadottir T, Rieder HL, Trebucq A, Waaler HT: Guidelines for conducting tuberculin skin test surveys in high prevalence countries. Tuberc Lung Dis 1996, 77(Suppl):1-20.

16. Xue P, Wang G, Zhang Y, Shao J, Jia S, Kou L: Preparation and application of PPD. Bulletin of Chinese microbiology 1993, 20:97-100.

17. Xu C, Liang Y, Li C, Dong W, Liang G, Xue A: Comparison of Chinesemade PPD and international common used PPD. Journal of Benbu Medical College 1985, 2:6-10.

18. Huang J: The current situation of the developing and application of Chinese-made PPD. The Journal of the Chinese Antituberculosis Association 1994, 16:141-143.

19. Kassim S, Zuber P, Wiktor SZ, Diomande FV, Coulibaly IM, Coulibaly D, Kadio A, Yapi A, Touré KC, Blekou PB, Irié B, Greenberg AE, Binkin NJ: Tuberculin skin testing to assess the occupational risk of Mycobacterium 
tuberculosis infection among health care workers in Abidjan, Cote d'Ivoire. Int J Tuberc Lung Dis 2000, 4:321-326.

20. Yanai H, Limpakarnjanarat K, Uthaivoravit W, Mastro TD, Mori T, Tappero JW: Risk of Mycobacterium tuberculosis infection and disease among health care workers, Chiang Rai, Thailand. Int J Tuberc Lung Dis 2003, 7:36-45.

21. Roth VR, Garrett DO, Laserson KF, Laserson KF, Starling CE, Kritski AL, Medeiros EA, Binkin N, Jarvis WR: A multicenter evaluation of tuberculin skin test positivity and conversion among health care workers in Brazilian hospitals. Int J Tuberc Lung Dis 2005, 9:1335-1342.

22. Centers for Disease Control: Targeted tuberculin testing and treatment of latent tuberculosis infection. MMWR 2000, 49:23-24.

23. Kayanja HK, Debanne S, King C, Whalen CC: Tuberculosis infection among health care workers in Kampala, Uganda. Int I Tuberc Lung Dis 2005, 9:686-688.

24. Seidler A, Nienhaus A, Diel R: Review of epidemiological studies on the occupational risk of tuberculosis in low-incidence areas. Respiration 2005, 2:431-446

25. Blumberg HM, Watkins DL, Berschling JD, Antle A, Moore P, White N, Hunter M, Green B, Ray SM, JMcGowan JE: Preventing the Nosocomial Transmission of Tuberculosis. Ann Intern Med 1995, 122:658-663.

26. Kolappan C, Gopi PG: Tobacco smoking and pulmonary tuberculosis. Thorax 2002, 57:964-966.

27. Pearson ML, Jereb JA, Frieden TR, Crawford JT, Davis BJ, Dooley SW, Jarvis WR: Nosocomial transmission of multidrug-resistant Mycobacterium tuberculosis: A risk to patients and health care workers. Ann Intern Med 1992, 117:191-196.

28. Sague C, Dooley S, Hutton M: Nosocomial transmission of multidrugresistant tuberculosis MDR-TB in an urban hospital. 31st Interscience Conference on Antimicrobial Agents and Chemotherapy Chicago, Illinois, United States; 1991, 140

29. Granich R, Binkin NJ, Jarvis WR, Simone PM, Rieder HL, Espinal MA, Kumaresan J: Guidelines for the prevention of tuberculosis in health care facilities in resource-limited settings. WHO/CDS/TB/99.269 Geneva, Switzerland: World Health Organization; 1999 [http://www.who.int/docstore/ gtb/publications/healthcare/PDF/WHO99-269.pdf.].

30. Raviglione M: XDR-TB. Entering the post-antibiotic era? Int I Tuberc Lung Dis 2006, 10:1185-1187.

31. Pereira SM, Dourado I, Barreto ML, Cunha SS, Ichiare MY, Hijjar MA, Goes JC, Rodrigues LC: Sensitivity and specificity of BCG scar reading in Brazil. Int $J$ Tuberc Lung Dis 2001, 5:1067-1070.

32. Li Y: Study on BCG scar and immunity after BCG vaccination. Journal of Practical Medical Techniques 2005, 12:2769-2770.

33. Pei Z, Yang D, Mao Q, Wang W: The relationship between BCG scar and PPD test. The Journal of the Chinese Antituberculosis Association 2003, 25:195-196.

\section{Pre-publication history}

The pre-publication history for this paper can be accessed here: http://www.biomedcentral.com/1471-2334/10/313/prepub

\section{doi:10.1186/1471-2334-10-313}

Cite this article as: He et al:: Infection control and the burden of tuberculosis infection and disease in health care workers in china: a cross-sectional study. BMC Infectious Diseases 2010 10:313.

\section{Submit your next manuscript to BioMed Central and take full advantage of:}

- Convenient online submission

- Thorough peer review

- No space constraints or color figure charges

- Immediate publication on acceptance

- Inclusion in PubMed, CAS, Scopus and Google Scholar

- Research which is freely available for redistribution

Submit your manuscript at www.biomedcentral com/submit
Biomed Central 